\title{
Spectrofluorimetric Method for the Determination of Tolterodine In Human Plasma and Pharmaceutical Preparations by Derivatization with Dansyl Chloride
}

Şerife Evrim TEKKELI

Department of Analytical Chemistry, Bezmialem Vakıf University School of Pharmacy, İstanbul, Turkey

\section{ABSTRACT}

Objective: Tolterodine (TOL) is an anti-muscarinic drug used for the symptomatic treatment of urinary incontinence. Analytical methods in the literature are not sensitive enough for the assay of drug substance biological fluids. To make up the deficit, we developed a sensitive, costreduced spectrofluorimetric method for the determination of TOL in plasma and pharmaceutical preparations.

Methods: TOL has a phenolic hydroxyl group that reacts with dansyl chloride. The spectrofluorimetric method is based on this reaction in the presence of a bicarbonate solution of $\mathrm{pH} 9.5$ to give a highly fluorescent derivative, which can be measured at $590 \mathrm{~nm}$ with an excitation wavelength at $360 \mathrm{~nm}$ in dichloromethane. Different experimental parameters affecting fluorescence intensity were optimized. The relationship between fluorescence intensity and TOL concentration was investigated.

Results: The developed method is linear in the concentration range of 5-60 $\mathrm{ng} \mathrm{mL}^{-1}$ with a minimum detectability of $0.136 \mathrm{ng} \mathrm{mL}^{-1}$. The recovery was $100.48 \%$.

Conclusion: A simple, cost-effective, and sensitive spectrofluorimetric method was developed and validated for the determination of TOL in human plasma and pharmaceutical preparations using dansyl chloride. According to this validation study, it is possible to use this proposed method for the routine analysis of the drug and for conducting bioavailability and bioequivalence studies with good accuracy and precision.

Keywords: Tolterodine, dansyl chloride, pharmaceutical preparations, plasma, derivatization

\section{Introduction}

Tolterodine (TOL) tartrate, (R)-N, N-di-isopropyl-3-(2-hydroxy-5 methylphenyl)-3-phenylpropanamine L-hydrogen tartrate, is an antimuscarinic active pharmaceutical ingredient used in the treatment of urinary incontinence. TOL has a very high affinity for cholinergic muscarinic receptors (4). Following $2 \mathrm{mg}$ oral administration, the maximum plasma concentration is $2-3 \mathrm{ng} \cdot \mathrm{mL}^{-1}(5)$.

There are several methods in literature for the analysis of TOL in biological fluids and pharmaceutical preparations. These methods are developed by spectrophotometry, high performance liquid chromatography, gas chromatography-mass spectrometry, and capillary electrophoresis techniques (9-12). The techniques require sophisticated instruments or rigorous sample preparation procedures. In addition, the mentioned spectrophotometric method is not sensitive enough for the analysis of TOL in biological fluids. Spectrofluorimetry enables a sensitive, simple, economical, and rapid analysis of drug substances by derivatization using appropriate reagents in biological fluids and pharmaceutical preparations. However, there is no method available in literature to spectrofluorimetrically analyze TOL. In this study, a new analytical method was developed based on the derivation of the TOL drug substance for the treatment of urinary incontinence using the dansyl chloride reagent. Dansyl chloride phenol is a commonly used fluorogenic derivatization indicator for the derivation of drugs containing primary and secondary amine groups (13-17). This reagent itself does not show fluorescence properties. 
It has a significant advantage because the reactive excess does not reveal any intervention status in the analysis. This method has been validated considering parameters, such as accuracy, precision, selectivity, linearity, and robustness. In addition, the developed method was applied to plasma and pharmaceutical preparations of TOL, and no interference arising from sample components was detected. The derivatization reaction between dansyl chloride and TOL is shown in Figure 1.

\section{Methods}

\section{Instruments}

Fluorescence measurements were made using the Hitachi spectrofluorometer (Model U-2900). Xenon lamps and $1 \mathrm{~cm}$ light path cells were used. The excitation and emission wavelengths were 360 and $590 \mathrm{~nm}$, respectively. The $\mathrm{pH}$ was measures using the WTW pH 526 digital $\mathrm{pH}$ meter.

\section{Reagents and Solutions}

TOL tartrate was obtained from Teva Tech (Israel). The pharmaceutical preparation TOLTEX Film Tablet (each film tablet contains $2 \mathrm{mg}$ of tolterodine tartrate) was purchased from a pharmacy and dansyl chloride Sigma-Aldrich was purchased from Germany. All chemicals and reagents were of analytical purity. For TOL, a stock solution of $1 \mu \mathrm{g} \cdot \mathrm{mL}^{-1}$ and various dilutions for the working solution were prepared in methanol.

Dansyl chloride was prepared fresh daily and as $2.0 \mathrm{mg} \cdot \mathrm{mL}^{-1}$ in acetone. Sodium bicarbonate $(0.1 \mathrm{M})$ was prepared in water and the $\mathrm{pH}$ was adjusted to 9.5 with sodium hydroxide. This solution can be stored at $4^{\circ} \mathrm{C}$ for 1 week.

\section{General Procedure}

Appropriate volumes of TOL stock solution $\left(1 \mu \mathrm{g} \cdot \mathrm{mL}^{-1}\right)$ between $0.025-0.300 \mathrm{~mL}$ were transferred to the test tubes and the volume was adjusted to $0.3 \mathrm{~mL}$ using methanol; $200 \mu \mathrm{L}$ of $\mathrm{pH} 9.5$ bicarbonate solution and $200 \mu \mathrm{L}$ of dansyl chloride solution were added to each tube. Each reaction mixture was incubated at $40^{\circ} \mathrm{C}$ for 10 minutes. The occurring derivatives were extracted into $5 \mathrm{~mL}$ of dichloromethane. The organic layer was separated and evaporated in a stream of nitrogen. A simultaneous blank determination was also performed similarly. The fluorescence intensity was measured at $590 \mathrm{~nm}$ with $360 \mathrm{~nm}$ excitation. Calibration curves were plotted as concentration against fluorescence intensity.

\section{Calibration Curve}

A series of standard solutions was prepared by diluting the TOL stock solution $\left(1 \mu \mathrm{g} \cdot \mathrm{mL}^{-1}\right)$. The process described in the general procedure section was applied $(n=5)$. Calibration curves were plotted as concentration against fluorescence intensity using the least-squares method. The equation used for the calibration curve was $\mathrm{I}_{\mathrm{f}}=\mathrm{aC}+\mathrm{b}$, where $\mathrm{C}$ ng is the drug concentration at $\mathrm{mL}^{-1}$, and $\mathrm{I}_{\mathrm{f}}$ is the fluorescence intensity.

\section{Analytical Procedure for Tablet Formulation}

A tablet powder containing $2 \mathrm{mg}$ of TOL was weighed and transferred to a $50 \mathrm{~mL}$ volumetric flask. Fifteen milliliters of methanol was added and it was extracted by stirring for 20 minutes in an ultrasonic bath. The volume was adjusted to $50 \mathrm{~mL}$ with methanol and the final mixture was filtered. The calibration curve was studied with the appropriate amount of filtrate as in the preparation section. The amount of the substance in the tablet was calculated through the calibration curve equation that was obtained.

\section{Analytical Procedure for Plasma Sample}

Plasma samples of $100 \mu \mathrm{L}$ were collected into test tubes and varying amounts of TOL solutions were added; subsequently, $250 \mu \mathrm{L} 0.1 \mathrm{~N} \mathrm{NaOH}$ was added. TOL was extracted to the plasma sample by mixing it with $3 \mathrm{~mL}$ of tbutylmethylether in a vortex mixer for 5 minutes and centrifuging at $2000 \mathrm{rpm}$ for 6 minutes. The organic phase was evaporated in a stream of nitrogen until dryness was achieved. The residue was dissolved in $0.2 \mathrm{~mL}$ of methanol. The analyses were performed as described in the "General procedure" section. Blank determinations were also carried out similarly. The recovery from plasma was calculated using the calibration curve. For the plasma samples, approval was received from the Bezmialem Foundation University Clinical Research Ethics Board and written informed consent was obtained

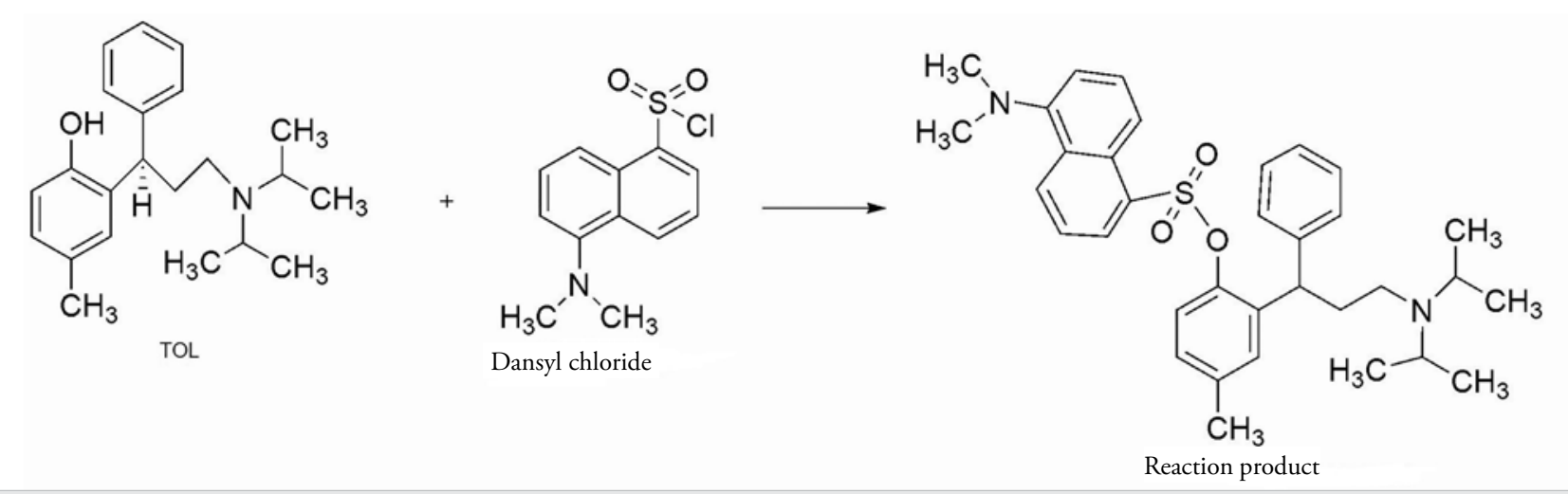


from volunteers.

\section{Results}

Due to a high sensitivity of fluorimetry, it has been selected for the analysis of TOL in plasma and pharmaceutical preparations. TOL contains a phenolic hydroxyl group in its chemical structure that makes it suitable for derivatization using dansyl chloride. Dansyl chloride is an appropriate and widely used marker for fluorimetric derivatization (13-17). The new method is based on the derivatization of drug substance with dansyl chloride. The derivatization reaction occurs at a $\mathrm{pH}$ of 9.5, and the fluorescence intensity of the resulting derivative was measured at $590 \mathrm{~nm}$ with 360 $\mathrm{nm}$ excitation in dichloromethane. The related spectrum is shown in Figure 2.

\section{Optimization of Experimental Parameters}

Various experiments have been carried out to determine the optimal values of the parameters affecting the derivatization reaction. Some parameters were varied, while others were kept fixed. Tests were performed for the extraction solvents using different solvents, such as chloroform, dichloromethane, diethyl ether, and benzene. It was found that the most efficient extraction was obtained using dichloromethane. The derivative formed under optimum conditions was found to be durable for 3 hours at room temperature. Firstly, the dansyl chloride concentration that provided the highest efficiency was specified. For this purpose, experiments were conducted using $0.02 \%$ dansyl chloride solutions in volumes ranging from 50 to $300 \mu \mathrm{L}$; $200 \mu \mathrm{L} 0.02 \%$ dansyl chloride was determined to be the most suitable concentration (Figure 3 ). The optimum reaction $\mathrm{pH}$ was then determined by forming derivatives at different $\mathrm{pH}$ values. The tests were performed using buffer solutions at $\mathrm{pH}$ ranging from 9 to 11 , considering that dansyl chloride reacts in alkaline environment. The highest fluorescence intensity was obtained at $\mathrm{pH} 9.5$ by the addition of $200 \mu \mathrm{L}$ buffer (Figure 4). The experiments for reaction medium temperature were carried out at $40^{\circ} \mathrm{C}$, $50^{\circ} \mathrm{C}$, and $60^{\circ} \mathrm{C}$. Optimum temperature was found to be $40^{\circ} \mathrm{C}$ and the waiting-period was 10 minutes. Figure 5 shows the effect of temperature and waiting-period on the

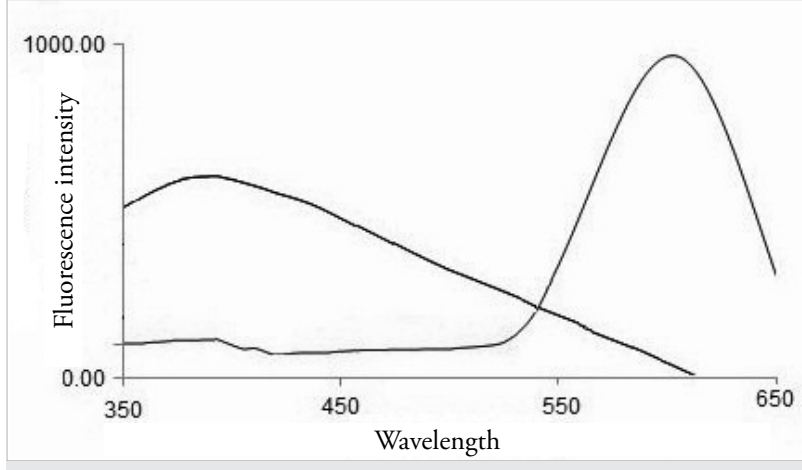

Figure 2. Derivative spectrums derivatization reaction. The molar ratio of the TOL to the dansyl chloride is also investigated using the Job's continuous variable method. When the molar ratio of the TOL to the dansyl chloride was 1 , it was concluded that the reaction occurred with the highest efficiency (18).

\section{Validation of the Developed Method}

The validation procedure was conducted in accordance with the criteria designated in the International Conference on Harmonization (19).

Calibration and Sensitivity: The method is linear at a concentration range of 30-60 ng. $\mathrm{mL}^{-1}$. The equation for the relationship between the concentration and fluorescence intensity is $\mathrm{I}_{\mathrm{f}}=14,975 \mathrm{C}-108,43$. The limit of detection (LOD) and the limit of quantitation (LOQ) were calculated as follows:

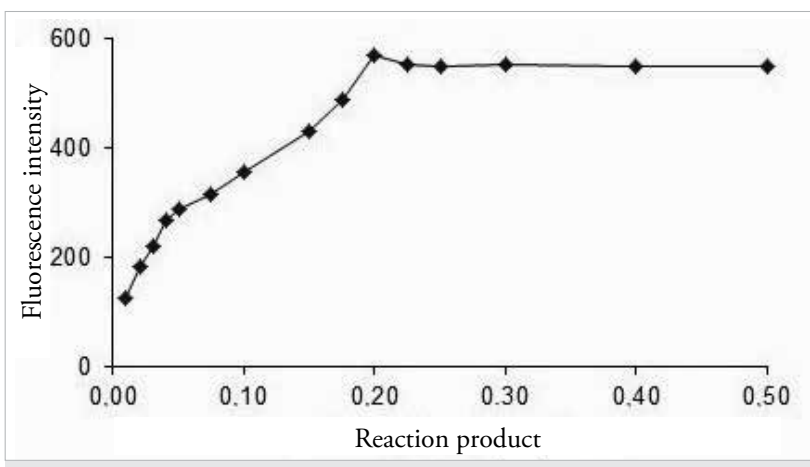

Figure 3. Effect of dansyl chloride volume on reaction efficiency $(0.5 \mathrm{mg} \cdot \mathrm{mL}-1)$

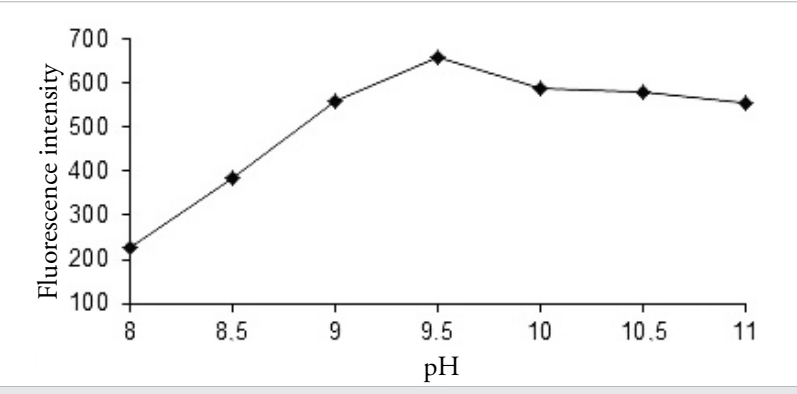

Şekil 4. Effect of pH on reaction efficiency

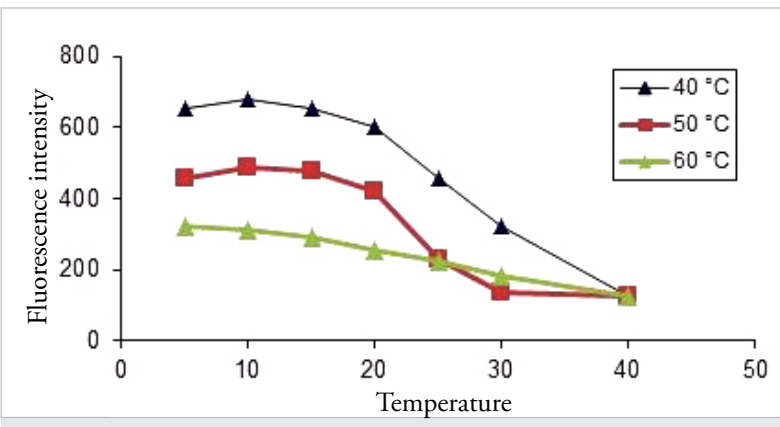

Figure 5. Effect of temperature and waiting-period on reaction efficiency 
$\mathrm{LOD}$ and $\mathrm{LOQ}={ }_{\mathrm{K}} \mathrm{SD}_{\mathrm{a} / \mathrm{b}} ; \mathrm{K}=3$ for $\mathrm{LOD}$ and $\mathrm{K}=10$ for $\mathrm{LOQ}$. $\mathrm{a}$ indicates the standard deviation of the cut-off point and $\mathrm{b}$ indicates the standard deviation of the slope. The analytical parameters of the method are listed in Table 1.

Accuracy, precision, and selectivity: A standard insertion technique was used to determine the accuracy of the method. Various quantities of pure TOL solution were added to plasma samples containing TOL at three different levels, which could be characterized as low, medium, and high. The recovery was calculated from the equation below.

Recovery\% $=\left[\left(\mathrm{C}_{\mathrm{t}}-\mathrm{C}_{\mathrm{u}}\right) / \mathrm{C}_{\mathrm{a}}\right] \times 100 \mathrm{Eqs}$

$\mathrm{C}_{\mathrm{t}}$ represents the total analyte concentration; $\mathrm{C}_{\mathrm{u}}$ represents the analyte concentration in the sample before the addition; $\mathrm{C}_{\mathrm{a}}$ represents the pure analyte concentration that is added. The results are given in Table 2. The recovery of 100,40\% shows that the method has a high accuracy. The selectivity of the method is a measure of the non-interference of sample components in the analysis. Tablet analyses did not interfere with any of the ancillary substances, and this was the result of placebo-based analyses. Two types of precisions were examined as intra-day and inter-day. TOL concentrations at three different levels were analyzed identically on the same day and on 7 consecutive days $(n=5)$. Relative standard deviation (RSD) was found to be $0.53 \%$ for intra-day and $1.02 \%$ for inter-day, and the results are shown in Table 2.

Robustness: It was determined that small modifications made under analytical conditions did not affect the method. For example, changes were made in the concentration of dansyl chloride at $\mathrm{a} / \mathrm{h} \% \pm 0,5$ temperature (optimum value $\pm 2{ }^{\circ} \mathrm{C}$ ) and waiting-period (optimum value $\pm 0.25 \mathrm{~min}$ ), and it was determined that the values of RSD did not change more than $2 \%$. The $\mathrm{pH}$ was determined to be the parameter that affected the results most. It was observed that the reaction could occur at a pH range of $9.5 \pm 0.2$.

\section{TOL Analysis in Tablets}

The newly developed method was applied to pharmaceutical products called TOLTEX Film Tablet ${ }^{\circ}$. The results shown in Table 3 were achieved, suggesting that the meth- od can be applied to tablets. In addition, the experiments revealed that there was no interference with tablet ancillary substances.

\section{TOL Analysis in Plasma samples}

In a study described in literature, a single $4 \mathrm{mg}$ dose of TOL was administered orally in 20 volunteers and pharmacokinetic parameters were calculated. The $\mathrm{C}_{\max }$ was calculated as $6.08 \pm 3.07 \mathrm{ng} \cdot \mathrm{mL}^{-1}$, was achieved in approximately 5.4 hours (10). TOL, including its pharmacokinetic values, can be analyzed using the newly developed method. The results of the plasma analysis are shown in Table 4.

Table 1. Results of the analytical parameters of the method

\begin{tabular}{|c|c|}
\hline Parameter & Value \\
\hline Wavelength (nm) & 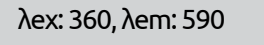 \\
\hline Concentration rangea (ng.mL-1) & $5.0-60.0$ \\
\hline \multicolumn{2}{|l|}{ Regression equationb } \\
\hline Cut-off $\pm S D$ & $108.43 \pm 0.68$ \\
\hline Slope \pm SD & $14.975 \pm 0.054$ \\
\hline Specification coefficient $\left(r^{2}\right)$ & 0.9981 \\
\hline \multicolumn{2}{|l|}{ Precision } \\
\hline Intra-dayc, RSD\% & 0.53 \\
\hline Inter-dayd, RSD\% & 1.02 \\
\hline LOD (ng.mL-1) & 0.136 \\
\hline LOQ (ng.mL-1) & 0.434 \\
\hline \multicolumn{2}{|l|}{${ }^{a}$ Average of 5 analyses } \\
\hline \multicolumn{2}{|c|}{$\begin{array}{l}\text { begression analysis was performed to determine the } \\
\text { relationship between TOL concentration and fluorescence } \\
\text { intensity }\end{array}$} \\
\hline \multicolumn{2}{|c|}{$\begin{array}{l}\mathrm{I}_{\mathrm{f}}=\mathrm{m} \mathrm{C}+\mathrm{b} \text { C ng.mL-1 TOL concentration (independent } \\
\text { Variable) }\end{array}$} \\
\hline \multicolumn{2}{|c|}{ and $\mathrm{I}_{\mathrm{f}}$ : fluorescence intensity (dependent variable) } \\
\hline \multicolumn{2}{|l|}{$\mathrm{cn}=5$ repetitions for each level } \\
\hline \multicolumn{2}{|l|}{ dResults of 7 different days } \\
\hline \multicolumn{2}{|c|}{$\begin{array}{l}\text { TOL: tolterodine; LOD: limit of detection; LOQ: limit of } \\
\text { quantitation; RSD: relative standard deviation; SD: standard } \\
\text { deviation }\end{array}$} \\
\hline
\end{tabular}

Table 2. Recovery results with standard insertion technique

\begin{tabular}{|c|c|c|c|c|c|}
\hline Presented Method & $\begin{array}{l}\text { Existing amount } \\
\left(\text { (ng. } \mathrm{mL}^{-1}\right) \mathrm{a}\end{array}$ & $\begin{array}{c}\text { Amount added } \\
\left.\text { (ng. } \mathrm{mL}^{-1}\right)\end{array}$ & $\begin{array}{c}\text { Total } \\
\text { amount } \\
\text { foundb }\end{array}$ & $\begin{array}{c}\text { Recovery (\%) } \\
\text { (ng.mL }{ }^{-1} \text { ) } \\
\text { (meantSD) }\end{array}$ & RSD (\%) \\
\hline & \multirow[t]{3}{*}{10} & 5 & $15.020 \pm 0.053$ & 100.40 & 0.35 \\
\hline & & 30 & $40.120 \pm 0.230$ & 100.40 & 0.57 \\
\hline & & 50 & $60.320 \pm 0.587$ & 100.64 & 0.59 \\
\hline \multicolumn{6}{|c|}{ aTOLTEX Film Tablet@ (2 mg) } \\
\hline \multicolumn{6}{|c|}{ 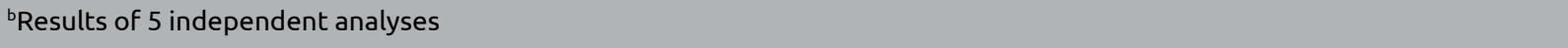 } \\
\hline \multicolumn{6}{|c|}{ RSD: relative standard deviation; SD: standard deviation } \\
\hline
\end{tabular}


Table 3. Tablette TOL analizi sonuçları $(n=5)$

\begin{tabular}{|c|c|c|c|c|}
\hline Presented Method & $\begin{array}{c}\text { Amounta } \\
\text { (mg/tablet) }\end{array}$ & Mean士SDb & Recovery (\%) & RSD (\%) \\
\hline & 2 & $2.01 \pm 0.015$ & 100.5 & 0.76 \\
\hline 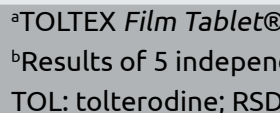 & deviation; SD: & viation & & \\
\hline
\end{tabular}

Table 4. Plazmada TOL analizi sonuçları $(n=5)$

\section{Presented Method}

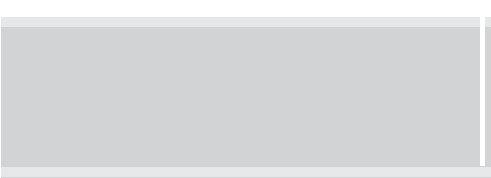

aResults of 5 independent analyses

TOL: tolterodine

\section{Amount added} (ng. $\mathrm{mL}^{-1}$ )

30.0

60.0

\begin{tabular}{|c|c|}
\hline 5.0 & $3.76 \pm 0.25$ \\
30.0 & $23.65 \pm 0.98$ \\
60.0 & $48.01 \pm 1.54$
\end{tabular}

\begin{tabular}{c}
$\begin{array}{c}\text { Found } \pm \text { SD } \\
\text { (ng.mL }\end{array}$ \\
\hline $3.76 \pm 0.25$ \\
$23.65 \pm 0.98$ \\
$48.01 \pm 1.54$
\end{tabular}

Recovery (\%)
75.23
78.84
80.01

RSD (\%)

6.65

4.14

3.21

\section{Conclusion}

In conclusion, the newly developed spectrofluorimetric method is quite practical and applicable. Complicated sample preparation procedures are not required. High accuracy and precision in the plasma and tablets of TOL provides quite accurate analysis. This method can be used in bioequivalence studies and in routine analyses.

Ethics Committee Approval: Ethics committee approval was received for this study.

Informed Consent: Written informed consent was obtained from patients who participated in this study.

Peer-review: Externally peer-reviewed.

Conflict of Interest: No conflict of interest was declared by the authors.

Financial Disclosure: The authors declared that this study has received no financial support.

\section{References}

1. Hu T, Wagner TH, Bentkover JD, Leblanc K, Zhou SZ, Hunt T. Costs of urinary incontinence and overactive bladder in the United States: A comparative study. Urology 2004; 63: 461-5. [CrossRef]

2. Andersson KE. Antimuscarinics for treatment of overactive bladder. Lancet Neurology 2004; 3: 46-53. [CrossRef]

3. Rovner ES. Trospium chloride in the management of overactive bladder. Drugs 2004; 64: 2433-46. [CrossRef]

4. Martindale, The Extra Pharmacopeia, 30th ed., UK: Pharmaceutical Press; 1993.

5. Hills CJ, Winter S', Balfour JA. Tolterodine. Drugs 1998; 55: 813-6. [CrossRef]

6. Fraihat S. Spectrophotometric determination of tolterodine tartrate via charge-transfer complexation reactions. Journal of Chemical Society of
7. Fraihat SM, Khatib HS. Indirect spectrophotometric determination of tolterodine tartrate in pure and pharmaceutical preparations. Asian Journal of Chemistry 2013; 25: 1887-90.

8. Sankar DG, Rao BD, Latha PVM, Krishna MV. Spectrophotometric determination of tolterodine tartarate and repaglinide. Asian Journal of Chemistry 2007; 19: 1616-18.

9. Macek J, Ptacek P, Klima J. Determination of tolterodine and its 5-hydroxymethyl metabolite in human plasma by hydrophilic interaction liquid chromatography-tandem mass spectrometry. Journal of Chromatography B: Analytical Technologies in the Biomedical and Life Sciences 2009; 877: 968-74. [CrossRef]

10. Zhang B, Zhang Z, Tian Y, Xu F. High performance liquid chromatography-electrospray ionization mass spectrometric determination of tolterodine tartrate in human plasma. J Chromatogr B Analyt Technol Biomed Life Sci 2005; 824: 92-8. [CrossRef]

11. Palmor L, Andersson L, Andersson T, Stenberg U. Determination of tolterodine and the 5-hydroxymethyl metabolite in plasma, plasma and urine using gas chromatography-mass spectrometry. Journal of Pharmaceutical and Biomedical Analysis 1997; 16: 155-65. [CrossRef]

12. Zhou L, Thompson R, Song S, Ellison D, Wyvratt MJ. A strategic approach to the development of capillary electrophoresis chiral methods for pharmaceutical basic compounds using sulfated cyclodextrins. Journal of Pharmaceutical and Biomedical Analysis 2002; 27: 541-53. [CrossRef]

13. Hermes LP, Sherry W, Chester LB, Eric Y. A semi automated 96 well plate method for the simultaneous determination of oral contraceptives concentrations in human plasma using ultra performance liquid chromatography coupled with tandem mass spectrometry. Journal of Chromatography B 2007; 852: 541-53.

14. Beaudry F, Guénette SA, Winterborn A, Marier JF, Vachon P. Development of a rapid and sensitive LC-ESI/MS/MS assay for the quantification of propofol using a simple off-line dansyl chloride derivatization reaction to enhance signal intensity. J Pharm Biomed Anal 2005; 39: 411-7. [CrossRef]

15. El-Enany N, Belal F, Rizk M. Spectrofluorimetric determination of oxamniquine in dosage forms and spiked human plasma through derivatization with 1 dimethylaminonaphthalene-5sulphonyl chloride. Journal of Fluorescence 2008; 18: 349-55. [CrossRef]

16. Cruces BC, Segura CA, Merino BE, Fernández GA. The use of dansyl chloride in the spectrofluorimetric determination of the synthetic an- 
Tekkeli ŞE. Spectrofluorimetric Analysis of Tolterodine

tioxidant butylated hydroxyanisole in foodstuffs. Talanta 1999; 50: 1099-108. [CrossRef]

17. Garcia SF, Cruces BC. Determination of the insecticide promecarb by fluorogenic labeling with dansyl chloride. Analyst 1991; 116: 851-8. [CrossRef]
18. Job P. Formation and stability of inorganic complexes in solution. Analytical Chemistry 1928; 9: 113-203.

19. ICH, In: International Conference on Harmonization of Technical Requirements for Registration of Pharmaceuticals for Human Use, Validation of Analytical Procedures: Text and Methodology Q2 (R1), 2005. 